\title{
Synthesis and Electrical Characterization of $\mathrm{ZrO}_{2}$ Thin Films on Si(100)
}

\author{
Vijay Ramkrishna Chinchamalatpure, Sunil Madhavrao Chore, Shikant Sahebrao Patil, \\ Gajanan Niranjan Chaudhari* \\ Nanotechnology Research Laboratory, Shri Shivaji Science College, Amravati, India \\ Email: "gnc4@indiatimes.com
}

Received June 25, 2011; revised August 13, 2011; accepted September 9, 2011

\begin{abstract}
The $\mathrm{ZrO}_{2}$ thin films deposited on $\mathrm{Si}(100)$ were successfully synthesized by sol-gel process and deposited by using spin-coating technique. The structural properties of $\mathrm{ZrO}_{2}$ thin films were investigated by X-Ray Diffraction (XRD), Scanning Electron Microscope (SEM), Fourier Transform Infrared Spectroscopy (FT-IR), and electrical properties were studied by conventional techniques like Capacitance-Voltage (C-V) measurement and Current-Voltage (I-V) measurement. The $\mathrm{XRD}$ of $\mathrm{ZrO}_{2}$ films shows the films crystallized and exists in two phases at $700^{\circ} \mathrm{C}$ calcinations temperature. The $\mathrm{C}-\mathrm{V}$ characteristics of all the dielectric films that involved distinct inversion, depletion, and accumulation were clearly revealed in MIS structure. I-V characteristics of $\mathrm{ZrO}_{2}$ thin films on Si shows decreased saturation current on calcinations temperatures. The XPS measurement reveals that a zirconium silicate interfacial layer has formed in the $\mathrm{ZrO}_{2} / \mathrm{Si}$ Systems.
\end{abstract}

Keywords: Sol-Gel Technique; $\mathrm{ZrO}_{2}$ Thin Film; C-V; I-V

\section{Introduction}

With the metal-oxide-semiconductor (MOS) device scaling high dielectric constant (high-k) oxides are currently widely investigated as potential candidates for replacement of conventional $\mathrm{SiO}_{2}$ gate oxide, zirconia based dielectrics is one of the most promising oxides because of their good thermal stability [1] and large band-offset in direct contact with the silicon substrate [2], high dielectric constant $(\varepsilon \approx 25)$, and large band gap $\left(\mathrm{E}_{\mathrm{g}} \approx 5.8 \mathrm{eV}\right)$ [3-5]. In addition to the above advantages, $\mathrm{ZrO}_{2}$ films are thermally stable with gate electrode materials during the deposition.

The oxide thin films are attracting an increasing interest because of their potential use as the material with high dielectric characteristics for manufacturing of the film capacitors and as a buffer layer with high chemical stability at creation of multi-layers systems [6]. Recently, oxide materials with high dielectric parameters have been suggested as an alternative to the currently used $\mathrm{SiO}_{2}$ gate dielectric for complementary application of metal oxide for using in semiconductor technology. Several oxide materials with high dielectric constant have been investigated as an alternative gate dielectric. However, their application is limited due to the interfacial reaction between dielectric materials and tradition microelectronic substrates, such as Si substrates, during the post annealing processes are known va-

"Corresponding author. rious technologies, which can be used for fabrication of $\mathrm{ZrO}_{2}$ films. But all suggested technologies include the stage of post-deposition annealing. Usually, optimum properties of $\mathrm{ZrO}_{2}$ films have been achieved when they are deposited on a hot substrate and are annealed after deposition. Therefore, it is necessary to develop technology for deposition of $\mathrm{ZrO}_{2}$ films at low temperature without considerable losses of their properties.

Various methods have been employed to prepare $\mathrm{ZrO}_{2}$ films, such as reactive sputtering [7], metal-organic chemical vapor deposition [8], atomic layer chemical vapor deposition [9], and pulsed-laser ablation deposition [10]. Among these methods spin coating technique is the more perspective and supple method for preparation of $\mathrm{ZrO}_{2}$ thin films, due to a high growth rate, simple means to drive of deposition processes. Hence, experimental definition of optimum parameters of spin coating technique for preparation of $\mathrm{ZrO}_{2}$ films with good characteristics on Si substrate with and without annealing is very important for practical applications.

Sol-gel spin-coating techniques have proved a popular means of fabrication ceramic and dielectric films in the submicrometer thickness range [11,12]. The basis of the technique is to coat a substrate with a polymeric precursor solution containing the requisite metal components in the required proportion, which then, because of solvent evaporation and chemical reactions, transforms to a gel layer. 
The organic components of the gel are then eliminated by various heat treatments to form the desired crystalline film. The main advantage of the sol-gel process is the ability to form inorganic structures at relatively low temperature. Moreover, the process is a cost-effective way to produce thin homogeneous inorganic films on large scales.

The microstructure and electrical properties of $\mathrm{ZrO}_{2}$ films on Si substrate prepared by spin coating technique were investigated. The microstructure of the films was characterized by X-Ray Diffraction (XRD) (Philips PW1710). Scanning Electron Microscopy (SEM) (VPFE-SEM, SU-PRA 35VP) and Fourier Transform Infrared Spectroscopy (FTIR).

The electrical properties of the deposited $\mathrm{ZrO}_{2}$ thin films were studied using Current-Voltage (I-V) and Capacitance-Voltage $(\mathrm{C}-\mathrm{V})$ measurements. The $\mathrm{C}-\mathrm{V}$ measurements were done at $1 \mathrm{MHz}$. The procedure of producing a MOS test structure is as follows. A layer of Al was deposited on top of the $\mathrm{ZrO}_{2}$ film via thermal evaporation process. At the back of the MOS test structure, a layer of Al was deposited on the Si substrate (pressure $\sim 1 \times 10^{-6}$ Torr). This was ensured that a good back contact was achieved. The area of each MOS capacitor was $0.1 \times 0.1$ $\mathrm{cm}^{2}$. The interface properties of $\mathrm{ZrO}_{2}$ on Si studied by $\mathrm{X}$-Ray Photoelectron Spectroscopy.

\section{Experimental Details}

$10 \mathrm{~g} \mathrm{Zr}\left(\mathrm{OC}\left(\mathrm{CH}_{3}\right)_{3}\right)_{4}$, zirconium tetra-tert-butoxide was initially dissolved in $100 \mathrm{ml}$ anhydrous ethanol and refluxed for $1 \mathrm{~h}$ at $50^{\circ} \mathrm{C} \sim 70^{\circ} \mathrm{C}$. After that $1 \mathrm{ml}$ nitric acid was added to control its $\mathrm{PH}$ and subsequently the solution was further stirred for $2 \mathrm{~h}$ at the same temperature range. The precursor solution was kept in a pressure bomb at $130^{\circ} \mathrm{C}$ up to 6 hours for gelification. This solution was then kept aside for two days so that it could undergo an aging process.

The thin films of $\mathrm{ZrO}_{2}$ was deposited by Spin-coating technique in air at a speed of $3000 \mathrm{rpm}$ for $30 \mathrm{sec}$ on a cleaned $\mathrm{Si}$ wafer with an area of $1 \mathrm{~cm} \times 1 \mathrm{~cm}$. Multiple coatings were performed to increase the film thickness for structural characterizations. After the spin coating process, the samples were independently inserted horizontal tube furnace withtemperatures of $400^{\circ} \mathrm{C}$ and $700^{\circ} \mathrm{C}$ for 2 hours. In this paper, we investigated the structural and electrical properties of $\mathrm{ZrO}_{2}$ films on $\mathrm{Si}$ substrate prepared by spin coating technique.

\section{Results and Discussion}

Figure 1 shows the XRD spectra of $\mathrm{ZrO}_{2}$ thin films deposited on $\mathrm{Si}$ and calcined at temperatures of $400^{\circ} \mathrm{C}$ and $700^{\circ} \mathrm{C}$. The peak (101) of tetragonal $\mathrm{ZrO}_{2}$ was observed at $400^{\circ} \mathrm{C}$. At $700^{\circ} \mathrm{C}$ calcinations temperature, in addition to tetragonal (101) peak, we could also observed monoclinic (022) peak of $\mathrm{ZrO}_{2}$. The results indicate that $\mathrm{ZrO}_{2}$

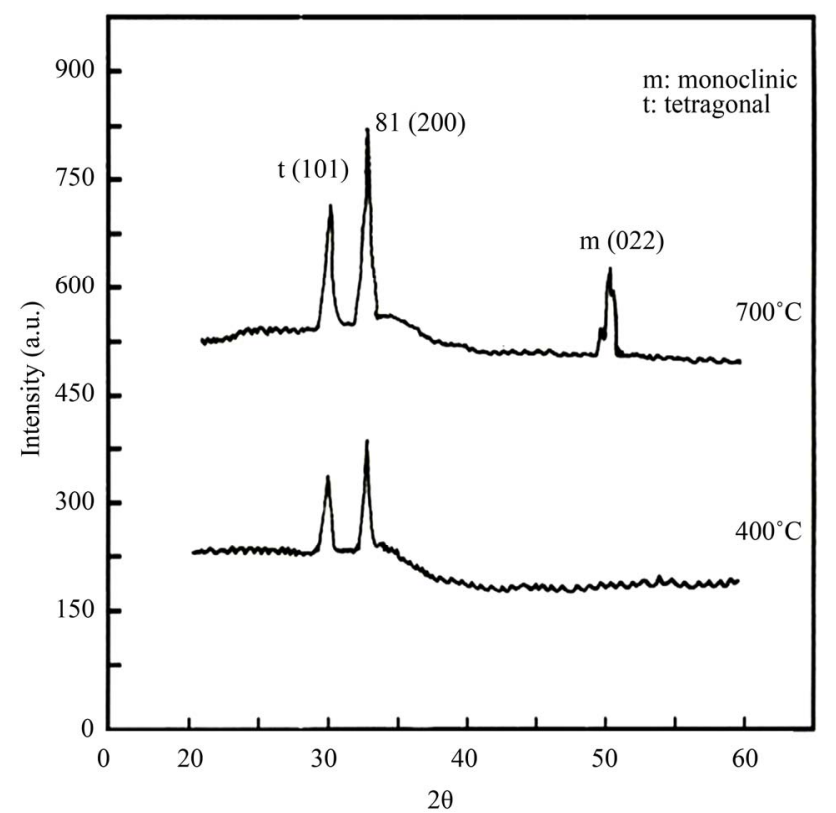

Figure 1. XRD Spectra of $\mathrm{ZrO}_{2}$ thin film on $\mathrm{Si}(100)$ substrates grown at $400^{\circ} \mathrm{C}$ and $700^{\circ} \mathrm{C}$.

films crystallized at a temperature higher than $400^{\circ} \mathrm{C}$ and two phases existed in the films deposited at $700^{\circ} \mathrm{C}$.

The surface morphology of deposited $\mathrm{ZrO}_{2}$ thin film was investigated using scanning electron microscopy, a field emission scanning electron microscope. The similar results were also observed by Zhu et al. [13]. Figure 2 shows the SEM of $\mathrm{ZrO}_{2}$ thin film calcined at $400^{\circ} \mathrm{C}$ and $700^{\circ} \mathrm{C}$. The thin films of $\mathrm{ZrO}_{2}$ shows a uniform, good coverage, and crack free surface. It has been observed that the average grain size increases with an increase in temperature from $400^{\circ} \mathrm{C}$ to $700^{\circ} \mathrm{C}$, due to the thermal expansion of zirconia.

Figure 3 shows the FT-IR spectra of $\mathrm{ZrO}_{2}$ thin films deposited by spin coating technique. The bands at $519 \mathrm{~cm}^{-1}$ and $792 \mathrm{~cm}^{-1}$ correspond to various vibrations of the $\mathrm{Zr}-\mathrm{O}$ bond. Dhar [14] investigated $\mathrm{ZrO}_{2}$ thin films deposited by MOCVD technique using beta ketoesterate complex and obtained similar type of microstructure.

It is to be noted that the FTIR spectra contain no features attribute to carbonate or hydroxide formation, even though the films were stored in the laboratory ambient.

Figure 4 shows the $\mathrm{C}-\mathrm{V}$ characteristics of as deposited and calcined at $400^{\circ} \mathrm{C}$ and $700^{\circ} \mathrm{C}$ of $\mathrm{ZrO}_{2}$ thin films on $\mathrm{Si}$. As deposited and calcined at $400^{\circ} \mathrm{C}$, the $\mathrm{C}-\mathrm{V}$ curve shows virtually flat which is an evidence of little modulation of the surface potential by the applied voltage. However when the film is subjected at $700^{\circ} \mathrm{C}$ calcinations temperature the $\mathrm{C}-\mathrm{V}$ plot shows a dramatic change in the $1 \mathrm{MHz}$ freq. $\mathrm{C}-\mathrm{V}$ behavior and considerable reduction in the frequency dispersion suggest a much closer approach to surface accumulation i.e. usually observed in the metal insulator semiconductor structure. Hence, the electrical properties of 


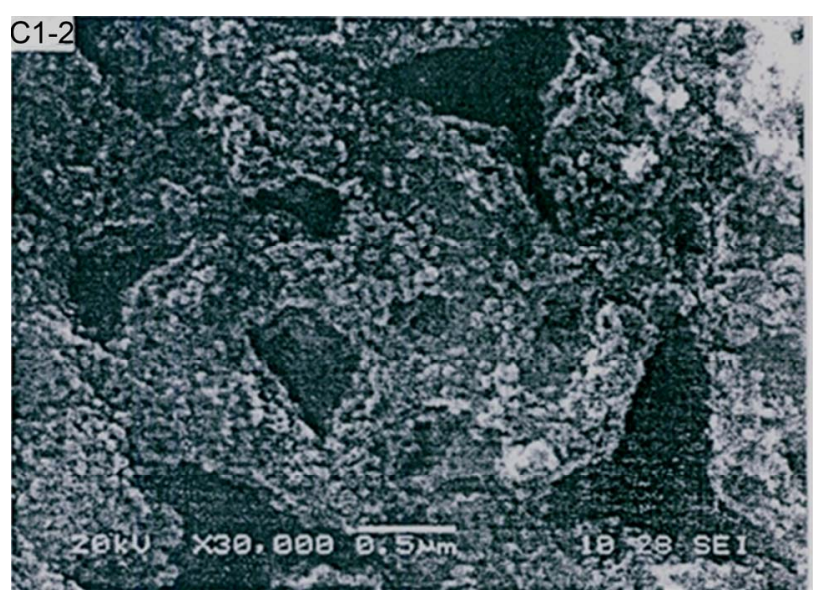

(a)

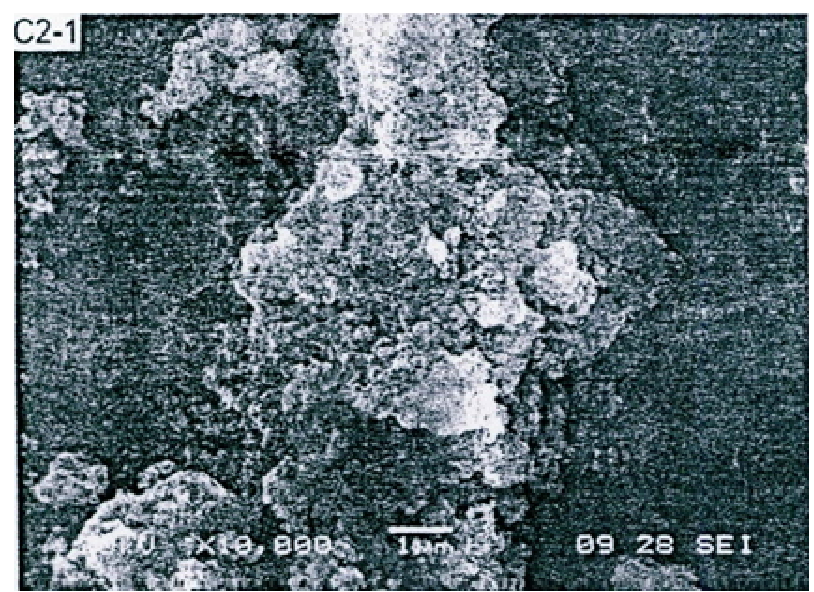

(b)

Figure 2. SEM micrograph of $\mathrm{ZrO}_{2}$ thin film annealed at (a) $400^{\circ} \mathrm{C}$ and (b) $700^{\circ} \mathrm{C}$.

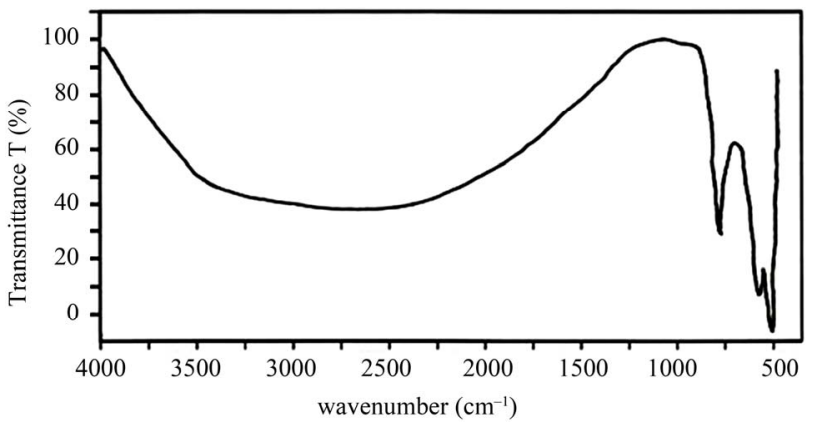

Figure 3. FTIR Spectra of $\mathrm{ZrO}_{2}$ thin film as deposited.

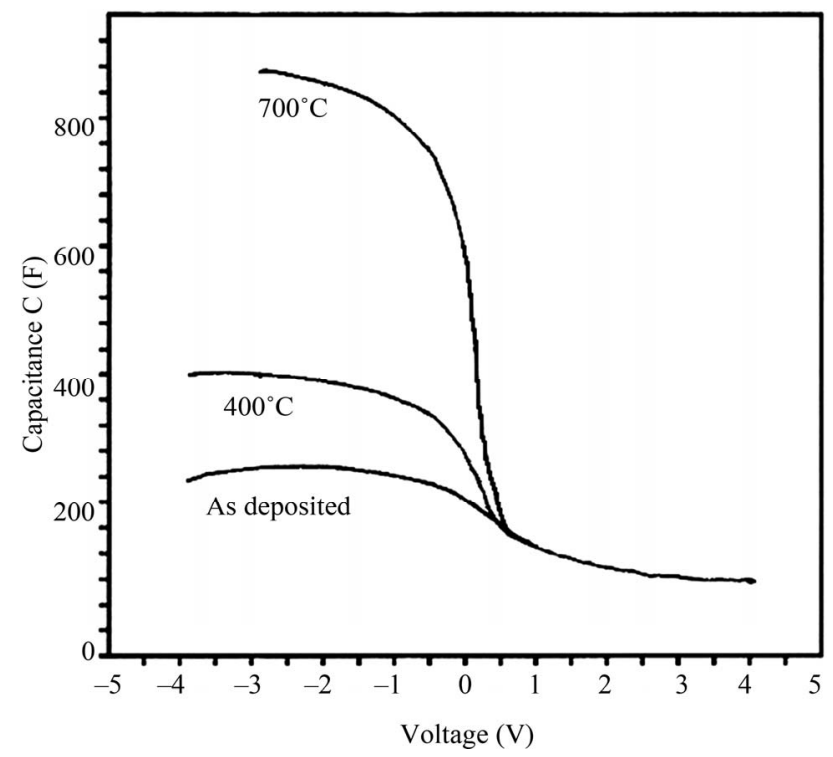

Figure 4. The $\mathrm{C}-\mathrm{V}$ characteristics of $\mathrm{ZrO}_{2}$ thin film on $\mathrm{Si}$ at as deposited, $400^{\circ} \mathrm{C}$ and $700^{\circ} \mathrm{C}$.

$\mathrm{ZrO}_{2} / \mathrm{Si}(100)$, MIS structure improved with annealing temperature at $700^{\circ} \mathrm{C}$. The measured capacitance density in accumulation was observed $1.95,1.55$ and $0.96 \mu \mathrm{fm}^{-2}$, which correspond to equivalent oxide thickness $\mathrm{t}=4.55$,
6.85 and $7.3 \mathrm{~nm}$ respectively. The dielectric constant of $\mathrm{ZrO}_{2}$ films is thickness dependent the dielectric constants are $\varepsilon \approx 19.8,20.9$ and 22.7 for $9.0,12.0$ and $21.0 \mathrm{~nm}$ $\mathrm{ZrO}_{2}$ samples respectively. J. Zhu et al. [15] show similar behavior of $\mathrm{ZrO}_{2}$ thin films deposited by pulsed laser deposition technique. The flat band voltage of $\mathrm{ZrO}_{2}$ films from the $\mathrm{C}-\mathrm{V}$ curves is in the range $0.86-0.88 \mathrm{~V}$. The dielectric constant of the $\mathrm{ZrO}_{2}$ film was calculated from the maximum capacitance (accumulation region) of the $\mathrm{C}-\mathrm{V}$ curves, according to the relationship

$$
C=\frac{\varepsilon \varepsilon_{0} A}{d}
$$

where $\varepsilon$ is the relative dielectric constant, $\varepsilon_{0}$ is the dielectric constant, $d$ is the oxide film thickness and $A$ is the area of the capacitor system surface.

Figure 5 shows the $\mathrm{I}-\mathrm{V}$ characteristics of $\mathrm{ZrO}_{2}$ thin films on $\mathrm{Si}$ calcined at $400^{\circ} \mathrm{C}$ and $700^{\circ} \mathrm{C}$. The saturation current decreased up on annealing. It was noticed that calcination temperatures affect the quality of the films. The improvement in leakage current by films calcined at $700^{\circ} \mathrm{C}$ may be attributed to the removal of the interface traps and oxide changes at the $\mathrm{ZrO}_{2}$ interface by $\mathrm{Zr}$ passivation. The $\mathrm{ZrO}_{2}$ film exhibited a leakage current density of $10^{-5}$ $\mathrm{A} / \mathrm{cm}^{2}$ which was further improved to $10^{-6} \mathrm{~A} / \mathrm{cm}^{2}$ after annealing. S. J. Wang et al. [16] have grown $\mathrm{ZrO}_{2}$ thin films on $\mathrm{Si}$ and obtained similar result. These low leakage currents due to several factors. $\mathrm{ZrO}_{2}$ possesses a wide gap (5 $7.8 \mathrm{eV})$, a high conduction band offset $(1.4 \mathrm{ev})$ and valance band $(3.3 \mathrm{eV})$ which means much high barrier heights for both electrons and holes carriers.

The ideality factor (n-value) was around 1.15 in the as deposited state shown in Figure 6 which was not good. A poor ideality factor is due to low carrier density in the substrates. The thin insulating layer at the interface might be a candidate for poor ideality factor in the as deposited state. $\mathrm{ZrO}_{2}$ thin films on $\mathrm{Si}$ at $400^{\circ} \mathrm{C}$ and $700^{\circ} \mathrm{C}$ did not change 


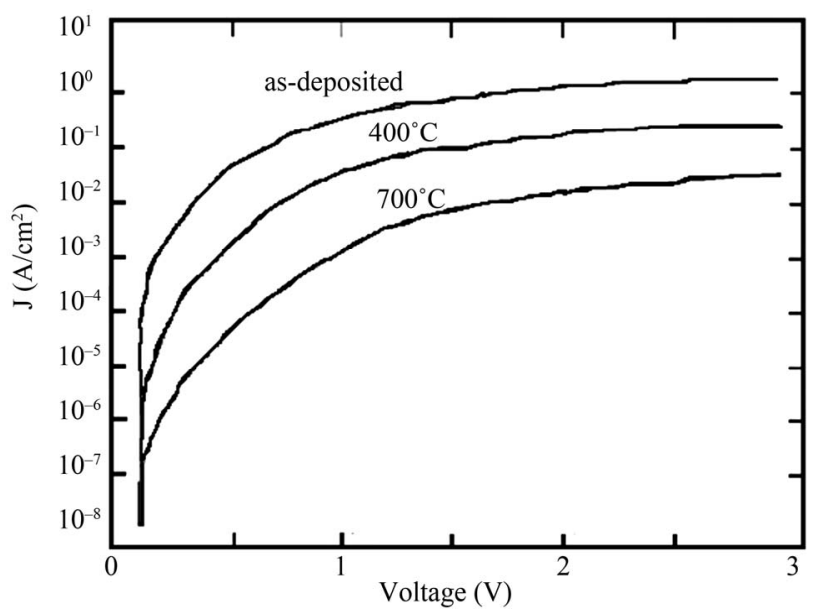

Figure 5. The I-V characteristics of $\mathrm{ZrO}_{2}$ thin film as deposited and annealed at $400^{\circ} \mathrm{C}$ and $700^{\circ} \mathrm{C}$.

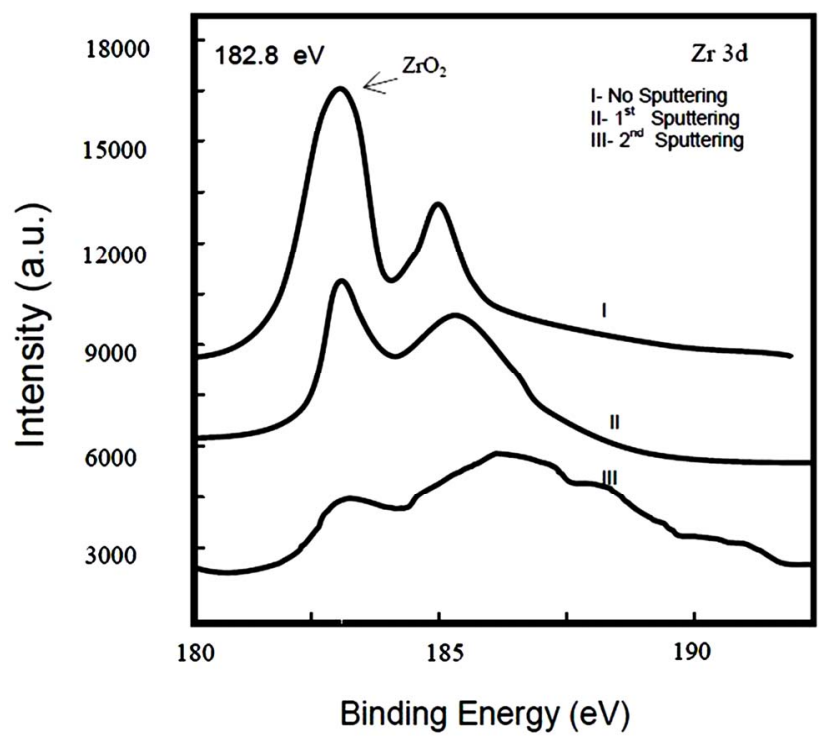

(a)

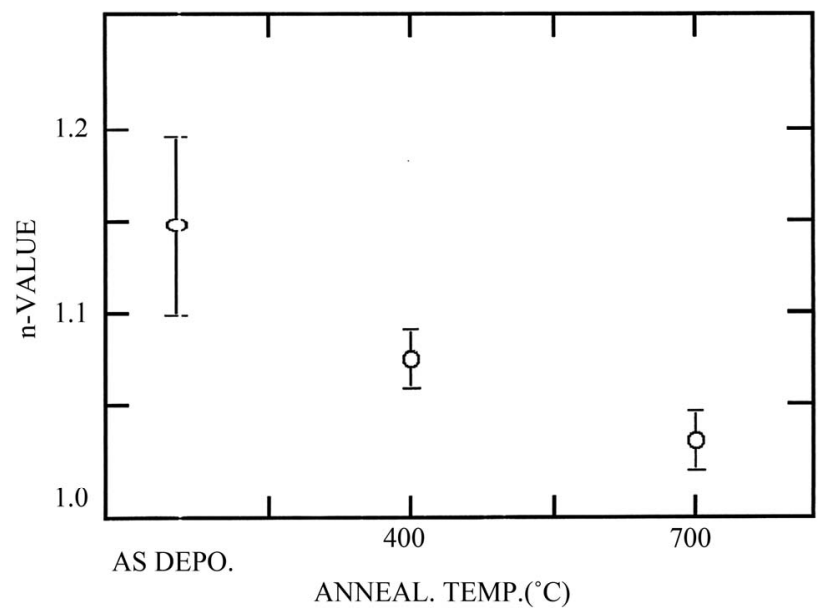

Figure 6. Change of the n-value (ideality factor) at different calcinations temperature.

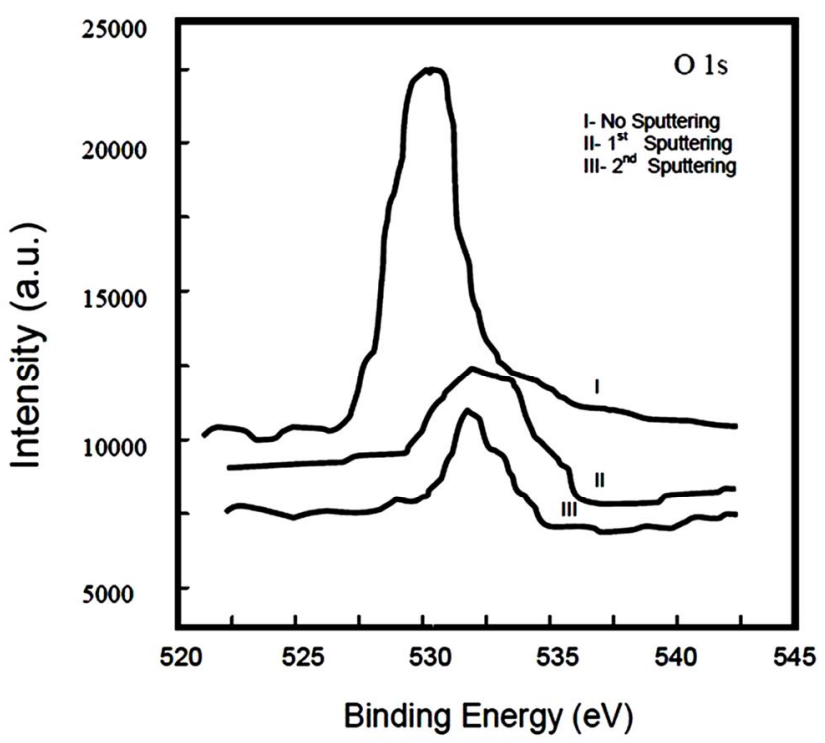

(b)

Figure 7. XPS Spectra of $\mathrm{ZrO}_{2}$ film deposited on Si with sputtering (a) $\mathrm{O}$ 1s (b) $\mathrm{Zr}$ 3d.

the barrier height very much, but improved the ideality factor slightly.

The XPS sputtering depth profile was carried out to investigate the features of the substrate interface and interfacial layer that were crucial to good performances of MOS structures. The $\mathrm{ZrO}_{2}$ film deposited on $\mathrm{Si}$ at $400^{\circ} \mathrm{C}$ was sputtered. The results are shown in Figure 7(a) Top scanning revealed $\mathrm{ZrO}_{2}$ bonding of both $\mathrm{O}$ 1s binding energy $530.2 \mathrm{eV}$ and $\mathrm{Zr} 3 \mathrm{~d}$ binding energy $182.8 \mathrm{eV}$. Obvious shifts to higher binding energy of $\mathrm{O} 1 \mathrm{~s}$ and binding energy of $\mathrm{Zr} 3 \mathrm{~d}$ energy were observed after the second sputtering. The $\mathrm{Zr} 3 \mathrm{~d}$ peak was shifted to higher binding energy for $\mathrm{ZrO}_{2}$. This also confirmed the formation of a zirconium silicate interfacial layer.

It is suggested that the greater donation of electron density to the Si-O bond in silicate should result in the higher binding energy of $\mathrm{Zr} 3 \mathrm{~d}$ in $\mathrm{Zr}-\mathrm{O}-\mathrm{Si}$ than that in $\mathrm{ZrO}_{2}$. The $\mathrm{Zr} 3 \mathrm{~d}$ peak after the second sputtering was relatively complicated, as shown in Figure 7(b). We attribute it to the fact that the interfacial layer is a mixture of non-stoichiometric $\mathrm{ZrOx}$ and $\mathrm{Zr}$ Silicate. This may be caused by $\mathrm{Ar}-$ gon ion sputtering damage which leads to a change of binding energy and is inevitable, no peak of binding energy $178.4 \mathrm{eV}$ of $\mathrm{Zr} 3 \mathrm{~d}$ corresponding to $\mathrm{Si}-\mathrm{Zr}$ bonding was observed [17], suggesting a lack of silicide formation at the substrate interface and Si-Zr bonding with in the interfacial layer.

\section{Conclusion}

The structural and electrical properties of $\mathrm{ZrO}_{2}$ thin films on $\operatorname{Si}(100)$ substrate by simple and low cost, spin coat- 
ing technique was investigated. The $\mathrm{XRD}$ of $\mathrm{ZrO}_{2}$ films shows the films crystallized at higher temperature and exists in two phases at $700^{\circ} \mathrm{C}$ calcinations temperature. The $\mathrm{C}-\mathrm{V}$ characteristics of all the dielectric films that involved distinct inversion, depletion, and accumulation were clearly revealed in MIS structure. I-V characteristics of $\mathrm{ZrO}_{2}$ thin films on $\mathrm{Si}$ shows decreased saturation current on calcinations temperatures. The XPS measurement reveals that a zirconium silicate interfacial layer has formed in the $\mathrm{ZrO}_{2} / \mathrm{Si}$ Systems.

\section{REFERENCES}

[1] K. J. Hubbard and D. G. Schlom, "Thermodynamic Stability of Binary Oxides in Contact with Silicon," Journal of Material Research, Vol. 11, No. 11, 1996, pp. 27572776. doi:10.1557/JMR.1996.0350

[2] R. Puthenkovilakam and J. P. Chang, "Valence Band Structure and Band Alignment at the $\mathrm{ZrO}_{2} / \mathrm{Si}$ Interface," Applied Physics Letters, Vol. 84, No. 8, 2004, pp. 13531355. doi:10.1063/1.1650547

[3] J. Robertson, "Band Offsets of Wide-Band-Gap Oxides and Implications for Future Electronic Devices," Journal of Vacuum Science Technology, Vol. B 18, 2000, p. 1785.

[4] K. S. Krisch, J. D. Bude and L. Manchanda, "Gate Capacitance Attenuation in MOS Devices with Thin Gate Dielectrics," IEEE Electron Device Letter, Vol. 17, No. 11, 1996, pp. 521-524. doi:10.1109/55.541768

[5] S. Chatterjeea, S. K. Samantaa, H. D. Banerjeeb and C. K. Maiti, "Electrical Properties of Stacked Gate Dielectric $\left(\mathrm{SiO}_{2} / \mathrm{ZrO}_{2}\right)$ Deposited on Strained SiGe Layers," Thin Solid Films, Vol. 422, No. 1-2, 2002, pp. 33-38. doi:10.1016/S0040-6090(02)00995-1

[6] Y. S. Lin, R. Puthenkovilakam, J. P. Chang, C. Bouldin, I. Levin, N. V. Nguyen, J. Ehrstein, Y. Sun, P. Pianetta, T. Conard, W. Vandervorst, V. Venturo and S. Selbrede, "Interfacial Properties of $\mathrm{ZrO}_{2}$ on Silicon," Journal of Applied Physics, Vol. 93, No. 10, 2003, pp. 5945-5952.

[7] R. Mahapatra, J. H. Lee, S. Maikap, G. S. Kar, A. Dhar, N.-M. H. Wang, D. Y. Kim, B. K. Mathur and S. K. Rayc, "Electrical and Interfacial Characteristics of Ultra-Thin $\mathrm{ZrO}_{2}$ Gate Dielectrics on Strain Compensated $\mathrm{SiGeC} / \mathrm{Si}$ Heterostructure," Applied Physics Letters, Vol. 82, No. 14, 2003, pp. 2320-2327. doi:10.1063/1.1566480
[8] S. Harasek, A. Lugstein, H. D. Wanzenboeck and E. Bertagnolli, "Slow Trap Response of Zirconium Dioxide Thin Films on Silicon," Applied Physics Letters, Vol. 83, No. 7, 2003, p. 1400. doi:10.1063/1.1602577

[9] A. Stesmans and V. V. Afanas'ev, "Si Dangling-BondType Defects at the Interface of $\mathrm{Si}(100)$ with Ultrathin Layers of $\mathrm{SiO}_{\mathrm{x}}, \mathrm{Al}_{2} \mathrm{O}_{3}$, and $\mathrm{ZrO}_{2}$," Applied Physics Letters, Vol. 80, No. 11, 2002, pp. 1957-1959. doi:10.1063/1.1448169

[10] J. M. Howard, V. Craciun, C. Essary and R. K. Singh, "Interfacial Layer Formation during High-Temperature Annealing of $\mathrm{ZrO}_{2}$ Thin Films on Si," Applied Physics Letters, Vol. 81, No. 18, 2002, pp. 3431-3433. doi:10.1063/1.1517407

[11] N. Sriprang, D. Kaewchina and J. D. Kennedy, "Processing and Sol Chemistry of a Triol-Based Sol-Gel Route for Preparing Lead Zirconate Titanate Thin Films," Journal of American Ceramic Society, Vol. 83, No. 8, 2000, pp. 1914-1920.

[12] X. R. Huang and Z. T. Huang, "Preparation of Asymmetric Alumina Membrane by Sol-Gel Techniques," Journal of Inorganic Material, Vol. 13, No. 4, 1998, p. 534.

[13] L. Q. Zhu, Q. Fang, G. He and M. Liu, "Interfacial and Optical Properties of $\mathrm{ZrO}_{2} / \mathrm{Si}$ by Reactive Magnetron Sputtering," Material Letter, Vol. 60, No. 7, 2006, pp. 888-891. doi:10.1016/j.matlet.2005.10.039

[14] S. Dhar and M. S. Dharmaprakash, "MOCVD of $\mathrm{ZrO}_{2}$ Films from Bis(t-Butyl-3-oxo-butanoato) Zirconium (IV): Some Therotical (Thermodynamics) and Experimental Aspects," Material Science, Vol. 31, 2008, pp. 67-72.

[15] J. Zhu and Z. G. Liu, "Structure and Dielectric Properties of Ultra-Thin $\mathrm{ZrO}_{2}$ Films for High-k Gate Dielectric Application Prepared by Pulsed Laser Deposition," Applied Physics, Vol. 78, No. 5, 2004, pp. 741-744. doi:10.1007/s00339-002-2025-0

[16] S. J. Wang and C. K. Ong, "Rapid Thermal Annealing Effect on Crystalline Yttria-Stabilized Zirconia Gate Dielectrics," Semiconductor Science and Technology, Vol. 18, No. 2, 2003, pp. 154-157. doi:10.1088/0268-1242/18/2/316

[17] T. S. Jeeon, J. M. White and D. I. Kwong, "Thermal Stability of Ultrathin $\mathrm{ZrO}_{2}$ Film on $\mathrm{Si}(100)$," Applied Physics Letter, Vol. 78, No. 3, 2001, p. 368. doi:10.1063/1.1339994 